\title{
Effects of dust storm events on emergency admissions for cardiovascular and respiratory diseases in Sanandaj, Iran
}

\author{
Seyyed Jamal Aldin Ebrahimi ${ }^{1}$, Leila Ebrahimzadeh ${ }^{1 *}$, Akbar Eslami $^{2}$ and Farzam Bidarpoor ${ }^{3}$
}

\begin{abstract}
Background: In recent years, increasing dust storms from western neighboring countries of Iran influenced western and central parts of the country. In this case, level of concentration of atmospheric particulate matter greater than $10 \mu \mathrm{m}\left(\mathrm{PM}_{10}\right)$ remained higher for several days compared to the levels before the event. Accordingly, Suspended particulate matters of dust storms in western Iran have caused PM $_{10}$ pollution in Sanandaj (capital of the Iranian province of Kurdistan) and other Iranian cities. The present study aimed to evaluate possible effects of dust storms on incidence of cardiovascular and respiratory diseases among residents of Sanandaj.
\end{abstract}

Materials and methods: Dust storm events defined based on the Environmental Protection Administration and Meteorological Announcements, 21 March 2009 to 21 June 2010. Data related to the dust events associated with cardiovascular and respiratory diseases were obtained from the Center for Disaster and Emergency Medicine of Sanandaj, Iran. PM10 concentration and air quality data were obtained from air quality monitoring agency of Kurdistan Provincial Directorate of Environment Protection. Daily $\mathrm{PM}_{10}$ measurements were performed automatically according to $\beta$-ray absorption. Data were statistically analyzed using SPSS and Pearson's correlation coefficient. Also, linear regression model was used to investigate the relationship between variables.

Results: The average $\mathrm{PM}_{10}$ levels during dust episodes $\left(187 \mathrm{\mu g} / \mathrm{m}^{3}\right)$ were significantly higher than the other days $\left(48.7 \mu \mathrm{g} / \mathrm{m}^{3}\right)$. In addition, correlation coefficient between $\mathrm{PM}_{10}$ level and number of cardiovascular and emergency service during dust events were equal to $0.48(P<0.05)$ and $0.19(P>0.05)$ respectively.

Conclusion: Our findings showed significant increase in emergency admissions for cardiovascular and respiratory diseases during dust storms episode in Sanandaj. Although correlation between respiratory diseases and dust storm events were statistically insignificant (0.19), numbers of cardiovascular diseases were significantly correlated with dust storm events (0.48).

\section{Introduction}

Arid or semi-arid environments, covering about 33\% of the total world land area, are the major origin of dust events (World Meteorological Organization, 2013 \#1). Dust storms occur when high winds at a threshold speed blow over low vegetation and soil areas that lack moisture content and are vulnerable to disturbance [1]. Increasing dust storms originating from western neighboring countries of Iran in recent years have influenced western and even

\footnotetext{
* Correspondence: leila.e980@gmail.com

'Department of Environmental Health Engineering, Air Pollution Control,

Kurdistan University of Medical Sciences, Sanandaj, Iran

Full list of author information is available at the end of the article
}

central parts of Iran. Furthermore, $\mathrm{PM}_{10}$ (particulate matter greater than $10 \mu \mathrm{m}$ ) concentrations remained greater than before the episode for several days. These dust storms are associated with various environmental and socio-economic problems [2].

Suspended particulate matters of dust storms in the west of Iran cause $\mathrm{PM}_{10}$ pollution in Sanandaj and other cities (Figure 1) [3]. Amanollahi et al. showed that dust storms in this region were created by wind erosion in desert of Northern Saudi Arabia, Western Iraq, and Eastern Syria. Average values of $\mathrm{PM}_{10}$ in Sanandaj ranged 107 to 


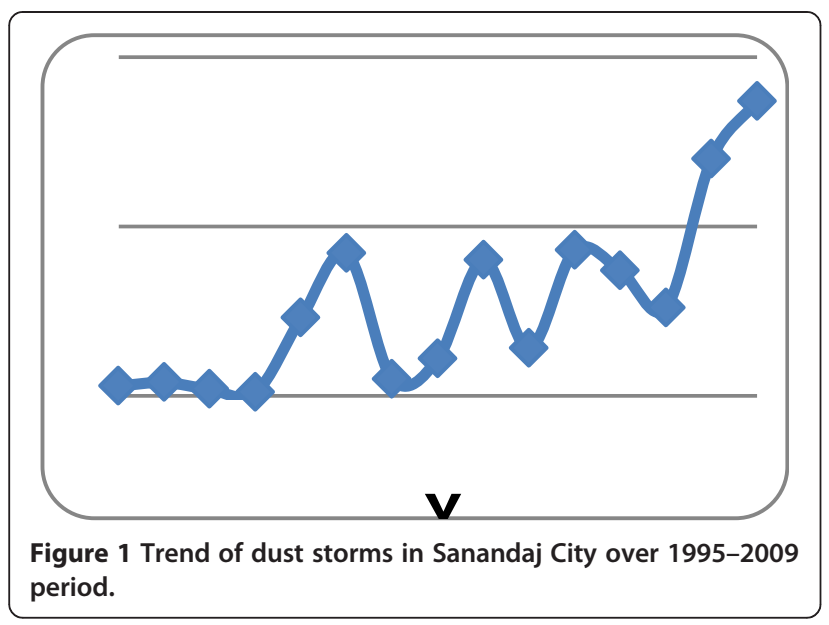

$2,976 \mu \mathrm{g} / \mathrm{m}^{3}$ on 3 and 5 July 2009 were recorded as sever dust storm with maximum $\mathrm{PM}_{10}$ concentration of $5,616 \mu \mathrm{g} / \mathrm{m}^{3}$ at 2 a.m. on 5 July 2009 [4]. A significant high concentration of $\mathrm{PM}_{10}$ on 5 July, compared to 8 July 2008, 10:30 was shown in Figure 2a (left) and b (right) [5].

In 2010, air quality index of Sanandaj was interpreted as good (19\%), moderate (57\%), unhealthy for sensitive groups $(15 \%)$, unhealthy $(5 \%)$, very unhealthy $(2 \%)$ and hazardous (2\%) [6]. In some cases, measured concentrations of particles in the dust storms reached to more than $6,000 \mu \mathrm{g} / \mathrm{m}^{3}$ [7]. Although, World Health Organization defines 24-hour average concentration of $\mathrm{PM}_{10}$ for ambient air and its annual average as 50 and $20 \mu \mathrm{g} / \mathrm{m}^{3}$ respectively [8].

$\mathrm{PM}_{10}$ particles cause or aggravate a number of diseases and mortalities due to cardiovascular or respiratory conditions. People with cardiovascular or respiratory diseases such as congestive cardiovascular failure, coronary artery disease, asthma or chronic obstructive pulmonary disease and old people are more likely refer to emergency care centers, hospitalized or even die in some cases. Furthermore, cardiac irregularities and cardiovascular attacks were attributed to exposure to particles $[9,10]$. In a study conducted in China by Meng et al. reported increasingly frequent hospitalization for pneumonia during dust storms [11]. According to the WHO report, during the late 1990s, exposure to $\mathrm{PM}_{10}$ has caused the occurrence of 700 annual deaths due to acute respiratory infections in children under 4 years old in Europe [12]. With the increase of $100 \mu \mathrm{g} / \mathrm{m}^{3}$ in the $24 \mathrm{~h}$ average concentration of $\mathrm{PM}_{10}$, pneumonia and chronic obstructive pulmonary disease cases increased by $19 \%$ and $27 \%$, respectively [13]. Ostro et al. (1999) found an association between $\mathrm{PM}_{10}$ and daily mortality in the Coachella Valley, a desert resort and retirement area east of Los angles (CA, USA) where coarse particles of geological origin typically comprise approximately $50-60 \%$ of $\mathrm{PM}_{10}$ and can exceed $90 \%$ during wind events [14]. The present study is aimed to evaluate possible effects of dust storms on the incidence of cardiovascular and respiratory diseases in Sanandaj during spring 2010.

\section{Methods}

\section{Study region}

Sanandaj, is located in western Iran (Figure 3). To assess the impacts of dust storms, we defined dust events based on Environmental Protection Administration and the Meteorological announcements from 21 March 2009 to 21 June 2010.

\section{Data on the incidence of diseases associated with dust events}

Patients with cardiovascular and respiratory diseases who received medical services from the CDMME in Sanandaj during dust event days were considered for the study. According to the international classification of diseases, following codes are available for the two diseases: cardiovascular diseases with international code of 459-390, and respiratory diseases with the international code of 519-490. Therefore, the diseases which were in the above range (according to the international classification of diseases) were considered as cardiovascular and respiratory diseases.

\section{Data on $\mathrm{PM}_{10}$ concentration and air quality in Sanandaj}

Sanandaj City possesses two pollution measurement stations (ECOTECH Company, Australia). These stations are capable of measuring air pollutants including carbon monoxide $(\mathrm{CO})$, sulfur anhydride $\left(\mathrm{SO}_{2}\right)$, particulate matter

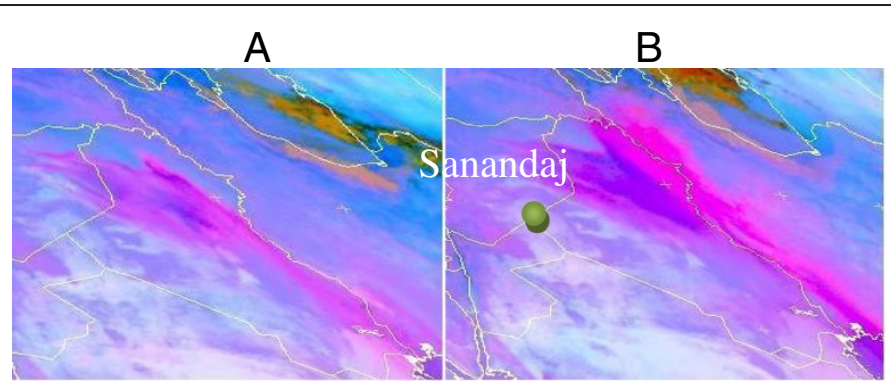

Figure 2 Dust is observed in pink with a tone more intensive the higher the dust content in the atmospheric column. (A) 16 June and 2008, (B) 17 June 2008, 10:30. 


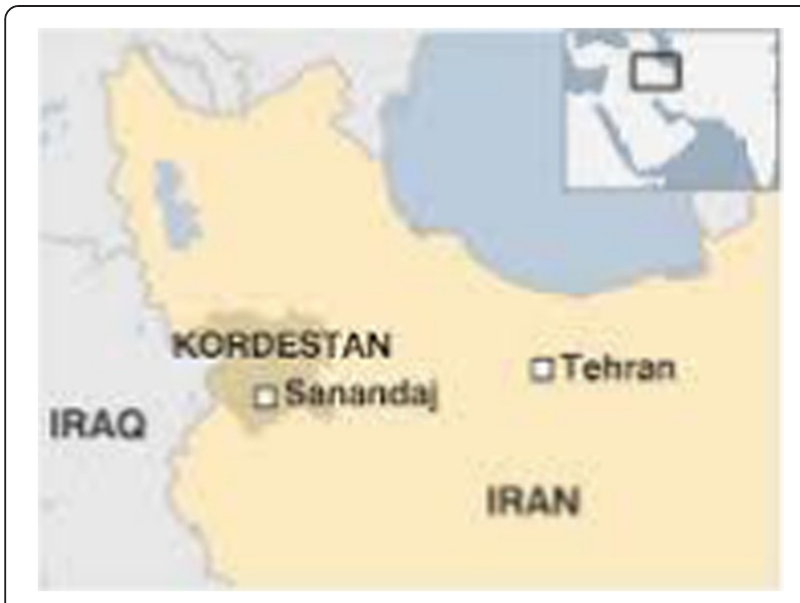

Figure 3 Location of Sanandaj and Kurdistan province in Iran.

with 10 microns in diameter $\left(\mathrm{PM}_{10}\right)$, nitrogen oxides $\left(\mathrm{NO}_{\mathrm{X}}\right)$ and ozone $\left(\mathrm{O}_{3}\right)$. The first station is located in the State Environmental Protection Administration and the second in the campus of the health department of Kurdistan University of Medical Sciences. The monitoring stations were fully automated and provided daily readings of $\mathrm{PM}_{10}$ levels (by $\beta$-ray absorption). Measurement data were frequently calibrated by a private company.

\section{Statistical analysis}

The diseases associated with dust storms and various concentrations of $\mathrm{PM}_{10}$ were analyzed using Microsoft Excel and linear regression. Equation of the regression line was used to indicate correlation between these two variables.

\section{Results}

The average $\mathrm{PM}_{10}$ level during dust event days $\left(187 \mu \mathrm{g} / \mathrm{m}^{3}\right)$ was significantly higher than the comparison days $\left(48.7 \mu \mathrm{g} / \mathrm{m}^{3}\right)$ (Figure 4$)$.

Table 1 shows air quality index for $\mathrm{PM}_{10}$ pollutant in spring. During 31 days of the season, Sanandaj city faced

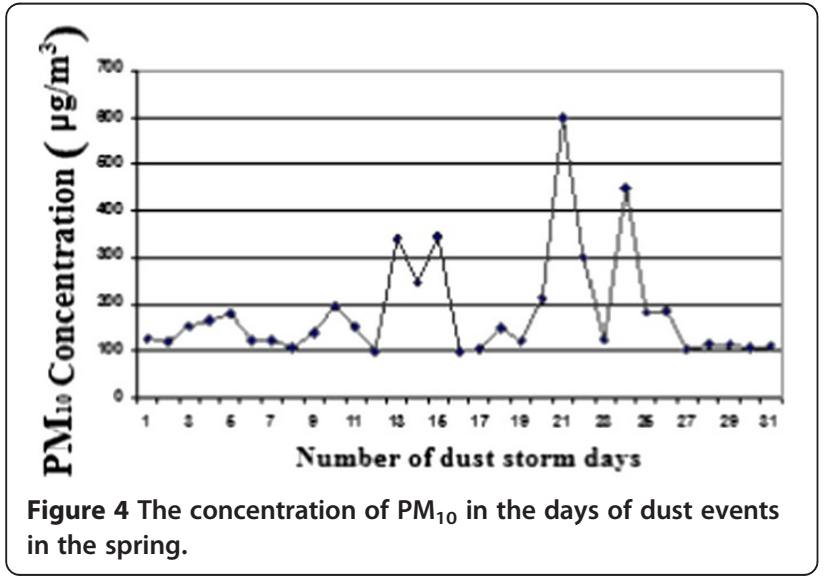

Table 1 Description of the air quality index for the days of spring for $\mathrm{PM}_{10}$ pollutant

\begin{tabular}{llllll}
\hline Unsafe & $\begin{array}{l}\text { Very } \\
\text { unhealthy }\end{array}$ & $\begin{array}{l}\text { Unhealthy } \\
\text { sensitive groups }\end{array}$ & $\begin{array}{l}\text { Unhealthy for } \\
\text { sealthy }\end{array}$ & Good \\
\hline 5 & 2 & 8 & 16 & 43 & 19 \\
\hline
\end{tabular}

dust problem, so that air quality index was interpreted as follows: unhealthy within 16 days for sensitive groups, 8 days unhealthy, very unhealthy for 2 days and 5 days as unsafe.

Figure 4 shows number of days with high level of $\mathrm{PM}_{10}$ in spring. The number on pollutant days on March-April, April-May and May-June were 7, 8 and 16 days, respectively.

Minimum, maximum, and average concentrations of $\mathrm{PM}_{10}$ during dust event days in spring are presented in Table 2. Average concentration of this pollutant in stormy days is $187 \mu \mathrm{g} / \mathrm{m}^{3}$. Minimum and maximum 24-hour concentrations of $\mathrm{PM}_{10}$ were equal to 100.4 and, $599.6 \mu \mathrm{g} / \mathrm{m}^{3}$, respectively during May-June, 2010.

Figure 5 shows the number of patients with cardiovascular and respiratory problems received medical services from CDMME in Sanandaj during dust events days. Nuumber of cardiovascular diseases is more than the number of respiratory diseases. This is why cardiovascular diseases are the primary cause of mortality in Sanandaj and thereby a high number of cardiovascular patients compared to patients with respiratory diseases. Furthermore, comparison of Figures 3 and 4 reveals possible correlation between the numbers of patients with respiratory and cardiovascular diseases who received medical services from the CDMME with the increase in $\mathrm{PM}_{10}$ concentration. Linear trend of cardiovascular diseases is more consistent with the linear trend of $\mathrm{PM}_{10}$ concentration (Figure 4).

Linear regression model was used to investigate the relationship between variables. According to Figure 6 and data from the CDMME and statistical analysis, correlation coefficient between $\mathrm{PM}_{10}$ level and number of cardiovascular patients received emergency service on dust events were equal to $0.48(\mathrm{P}<0.05)$ which indicates a significant positive correlation between these two variables.

The correlation coefficient between concentration of $\mathrm{PM}_{10}$ and number of respiratory patients receiving medical emergency services on dust events days was $0.19(\mathrm{P}>0.05)$ (Figure 7). This indicates no significant linear correlation between these two variables.

Table 2 The maximum, minimum and, average daily levels of $\mathrm{PM}_{10}$ on stormy days of spring

\begin{tabular}{lllll}
\hline Season & $\begin{array}{l}\text { Maximum } \\
\mathbf{g} / \mathbf{m}^{\mathbf{3}} \boldsymbol{\mu}\end{array}$ & $\begin{array}{l}\text { Minimum } \\
\boldsymbol{\mu g} / \mathbf{m}^{\mathbf{3}}\end{array}$ & $\begin{array}{l}\text { Average } \\
\boldsymbol{\mu g} / \mathbf{m}^{\mathbf{3}}\end{array}$ & $\begin{array}{l}\text { Standard } \\
\text { deviationa } \approx \mathbf{0 . 9 5}\end{array}$ \\
\hline Spring & $6 / 599$ & $4 / 100$ & 187 & $2 / 115$ \\
\hline
\end{tabular}




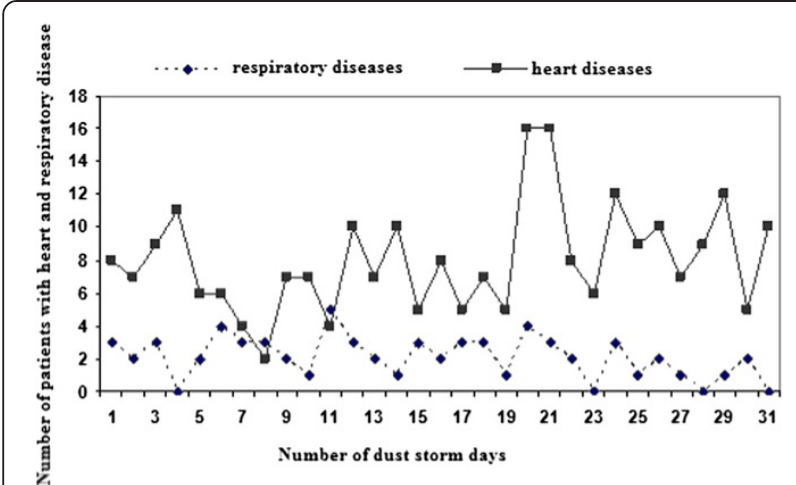

Figure 5 The number of patients with cardiovascular and respiratory diseases received medical emergency services on dust events in spring.

Table 3 shows equations of the regression line and correlation coefficients between concentration of PM10 and the occurrence of respiratory and cardiovascular diseases. Our results showed $100 \mu \mathrm{g} / \mathrm{m}^{3}$ increase in $\mathrm{PM}_{10}$ concentration resulted in $1.351 \%$ and $0.021 \%$ increase in cardiovascular and respiratory diseases, respectively.

\section{Discussion}

Average $\mathrm{PM}_{10}$ level during dust event days $\left(187 \mu \mathrm{g} / \mathrm{m}^{3}\right)$ was significantly higher than the comparison days $\left(48.7 \mu \mathrm{g} / \mathrm{m}^{3}\right)$. During storm event days other pollutants related to combustion $\left(\mathrm{SO}_{2}, \mathrm{NO}_{2}, \mathrm{CO}\right)$ were almost constant; therefore, any effects due to the occurrence of dust storms can be attributed to an increase in $\mathrm{PM}_{10}$ concentration.

Kwon et al. showed that during dust storms $\mathrm{PM}_{10}$ concentration from geological sources reached $50 \%$ to $60 \%$ and sometimes to $90 \%$ [15]. Several studies have shown that in dust storms, effect of fine particles is higher than coarse particles [16-18]. However, Dockery et al. found no difference between the impact of fine and coarse particles [19]. Castillejos et al. conducted a daily timeseries analysis of mortality in relation to measurements

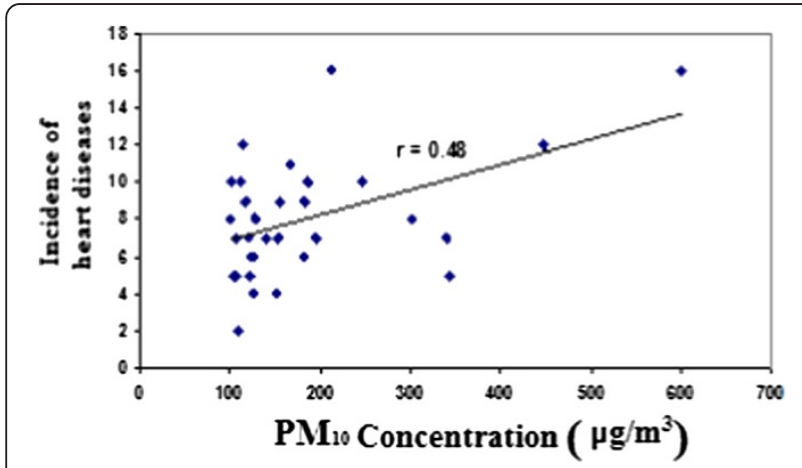

Figure 6 The concentration of $\mathrm{PM}_{10}$ and the incidence of cardiovascular diseases on dust events.

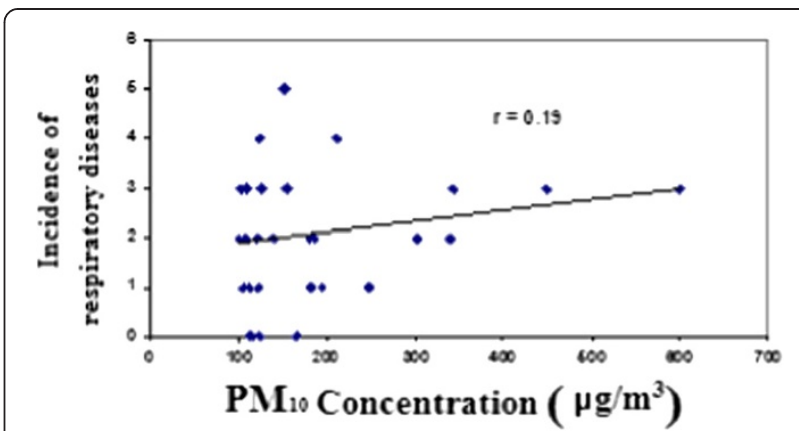

Figure 7 The concentration of $\mathrm{PM}_{10}$ and the occurrence of respiratory diseases on dust events.

of PM2.5, PM10, and PM10-2.5 in south western Mexico City in the years 1992-1995, they found that the effect of coarse particles was stronger for respiratory diseases than for total mortality, cardiovascular diseases, or other non injury causes of death [20].

Hefflin et al. investigated the effect of dust storms on the number of emergency referrals in one of the southeastern states of Washington. During the dust storm events, 24 h PM10 concentrations in two consecutive days were more than $1000 \mu \mathrm{g} / \mathrm{m}^{3}$. Numbers of patients with bronchitis referring to the center were about 3.5\% per each $100 \mu \mathrm{g} / \mathrm{m}^{3}$ increase in PM10 concentration [21]. According to the results of the present study, for each $100 \mu \mathrm{g} / \mathrm{m}^{3}$ increase in the PM10 concentration, $1.35 \%$ and $0.021 \%$ increase in the incidence of cardiovascular and respiratory diseases was observed respectively.

Pan et al. found a significant correlation between the dust storms and increased hospital admissions. The most common diseases during stormy days were pharynx, larynx, cornea, nasal and cervical inflammations [22].

Yang et al. investigated the effect of dust storms on the occurrence of cerebrovascular accident, 7 days before and 7 days after the dust storms events in Taiwan during 1996-2001. They found a significant difference between the storms events and the incidence of stroke 3 days after the events. However, no statistically significant difference was observed between the storm events and the incidence of cardiovascular attacks 3 days after the events [11].

Chiu et al. studied possible association between dust storms and hospital admissions of chronic obstructive pulmonary diseases 7 days before and after the dust

Table 3 The correlation between the concentration of $\mathrm{PM}_{10}$ and the incidence of cardiovascular and respiratory diseases

\begin{tabular}{lll}
\hline $\begin{array}{l}\text { Correlation } \\
\text { coefficient }\end{array}$ & $\begin{array}{l}\text { Regression line } \\
\text { equation }\end{array}$ & Title \\
\hline 0.48 & $y=0.0135 x+5.5029$ & Cardiovascular diseases \\
0.19 & $y=0.0021 x+1.7$ & Respiratory diseases \\
\hline
\end{tabular}


storms events in Taiwan during 1996-2001. They found no significant difference between storm events and the incidence of chronic obstructive pulmonary diseases [23].

Chen et al. studied effect of dust storms on hospital admissions of cardiovascular diseases, 7 days before and 7 days after the dust storms events in Taiwan during 1996-2001. No significant differences were found between storms events and cardiovascular conditions [24].

\section{Conclusions}

Occurrence of dust storms could increase the probability of cardiovascular and respiratory diseases in Sanandaj. Although the correlation between respiratory diseases and the dust storms was not statistically significant, a statistically significant correlation was observed between cardiovascular diseases and dust storms events.

\section{Competing interests}

The authors declare that they have no competing interest.

\section{Authors' contributions}

All authors have equal contribution in the study. All authors read and approved the final manuscript.

\section{Acknowledgements}

This study was a research priority in Kurdistan University of Medical Sciences. Hereby, many thanks go to the Deputy of Research and Deputy of Health, Kurdistan University of Medical Sciences for their cooperation and assistance.

\section{Author details}

'Department of Environmental Health Engineering, Air Pollution Control, Kurdistan University of Medical Sciences, Sanandaj, Iran. ${ }^{2}$ Department of Environmental Health Engineering, Shahid Beheshti University of Medical Sciences, Tehran, Iran. ${ }^{3}$ Department of Environmental Health Engineering, Kurdistan University of Medical Sciences, Sanandaj, Iran.

Received: 27 April 2014 Accepted: 27 July 2014

Published: 6 August 2014

\section{References}

1. World Meteorological Organization: Establishing a WMO Sand and Dust Storm Warning Advisory and Assessment System Regional Node for West Asia: Current Capabilities and Needs. 2013, 1121.

2. Gerivani H, Lashkaripour GR, Ghafoori M: The source of dust storm in Iran: a case study based on geological information and rainfall data. Carpathian J Earth Environ Sci 2011, 6(1):297-308.

3. Amanollahi J, Kaboodvandpour S, Abdullah AM, Ramli MF: Accuracy assessment of moderate resolution image spectroradiometer products for dust storms in semiarid environment. Int J Environ Sci Technol 2011, 8(2):373-380.

4. Amanollahi J, Tzanis C, Abdullah AM, Ramli MF, Pirasteh S: Development of the models to estimate particulate matter from thermal infrared band of Landsat Enhanced Thematic Mapper. Int J Environ Sci Technol 2013, 10(6):1245-1254

5. Karmaliani R, Asad N, Bann C, Moss N, Pasha EM, Wright LL, Goldenberg RL: Prevalence of anxiety, depression and associated factors among pregnant women of Hyderabad, Pakistan. Int J Soc Psychiatry 2009, 55(5):414-424.

6. Ebrahimi S, Ebrahimzadeh L, Habibzadeh F, Malekafzali FH, Ghavami A: Assess the severity of dust storms and air quality index in Sanandaj 2010. In 14th National Congress on Environmental Health. Yazd University of Medical Sciences; 2011:1-36.

7. Naddafi A: Air pollution with the emphasis on particulate matters and their health and environmental impacts. In 12th National Congress on Environmental Health. Shahid Behashti University of Medical Sciences; 2009.
8. WHO: Final Revision to the Ambient Air Quality Standards for Particulate Pollution. 2006.

9. Chen YS, Sheen PC, Chen ER, Liu YK, Wu TN, Yang CY: Effects of Asian dust storm events on daily mortality in Taipei, Taiwan. Environ Res 2004, 95(2):151-155.

10. Yang CY, Chen YS, Chiu HF, Goggins WB: Effects of Asian dust storm events on daily stroke admissions in Taipei, Taiwan. Environ Res 2005, 99(1):79-84.

11. Meng Z, Lu B: Dust events as a risk factor for daily hospitalization for respiratory and cardiovascular diseases in Minqin, China. Atmos Environ 2007, 41(33):7048-7058.

12. WHO: Comparative Quantification of Health Risks. 2nd edition. Geneva: H-J, Cho S-H, Chun Y, Lagarde F, Pershagen G: Effects of the Asian dust events on daily mortality in Seoul, Korea. Environ Res 2002, 90(1):1-5.

16. Schwartz J, Dockery DW, Neas LM: Is daily mortality associated specifically with fine particles? J Air Waste Manage Assoc 1996, 46(10):927-939.

17. Levy Jl, Hammitt JK, Spengler JD: Estimating the mortality impacts of particulate matter: what can be learned from between-study variability? Environ Health Perspect 2000, 108(2):109.

18. Anderson HR, Bremner SA, Atkinson RW, Harrison RM, Walters S: Particulate matter and daily mortality and hospital admissions in the west midlands conurbation of the United Kingdom: associations with fine and coarse particles, black smoke and sulphate. Occup Environ Med 2001, 58(8):504-510

19. Dockery DW, Schwartz J, Spengler JD: Air pollution and daily mortality: associations with particulates and acid aerosols. Environ Res 1992, 59:362-373

20. Castillejos VHB-A, Dockery DW, Gold DR DLM: Airborne coarse particles and mortality. Inhal Toxicol 2000, 12(S1):61-72.

21. Hefflin BJ, Jalaludin B, McClure E, Cobb N, Johnson CA, Jecha L, Etzel RA: Surveillance for dust storms and respiratory diseases in Washington State, 1991. Arch Environ Health: Int J 1994, 49(3):170-174.

22. Pan X-C, Liu J: Study on health effects of dust storms in China. In 22nd Annual Conference, Climate Change and Environmental Health. Seoul, Korea: 2010. 22(1):S26-S27.

23. Chiu H-F, Tiao MM, Ho SC, Kuo HW, Wu TN, Yang CY: Effects of Asian dust storm events on hospital admissions for chronic obstructive pulmonary disease in Taipei, Taiwan. Inhal Toxicol 2008, 20(9):777-781.

24. Chen Y-S, Yang C-Y: Effects of Asian dust storm events on daily hospital admissions for cardiovascular disease in Taipei, Taiwan. J Toxic Environ Health A 2005, 68(17-18):1457-1464.

doi:10.1186/s40201-014-0110-x

Cite this article as: Ebrahimi et al:: Effects of dust storm events on emergency admissions for cardiovascular and respiratory diseases in Sanandaj, Iran. Journal of Environmental Health Science \& Engineering 2014 12:110

\section{Submit your next manuscript to BioMed Central and take full advantage of:}

- Convenient online submission

- Thorough peer review

- No space constraints or color figure charges

- Immediate publication on acceptance

- Inclusion in PubMed, CAS, Scopus and Google Scholar

- Research which is freely available for redistribution 